\title{
New Relevant Pesticide Transformation Products in Groundwater Detected Using Target and Suspect Screening for Agricultural and Urban Micropollutants with LC-HRMS
}

\author{
Karin Kiefer ${ }^{1,2}$, Adrian Müller ${ }^{1}$, Heinz Singer ${ }^{1}$, Juliane Hollender ${ }^{1,2 *}$ \\ 1Eawag: Swiss Federal Institute of Aquatic Science and Technology, Ueberlandstrasse 133, \\ 8600 Duebendorf, Switzerland \\ ${ }^{2}$ Institute of Biogeochemistry and Pollutant Dynamics, Universitätstrasse 16, ETH Zürich, \\ 8092 Zurich, Switzerland
}

*Corresponding author: juliane.hollender@eawag.ch

\section{Accepted Manuscript}

DOI: https://doi.org/10.1016/i.watres.2019.114972

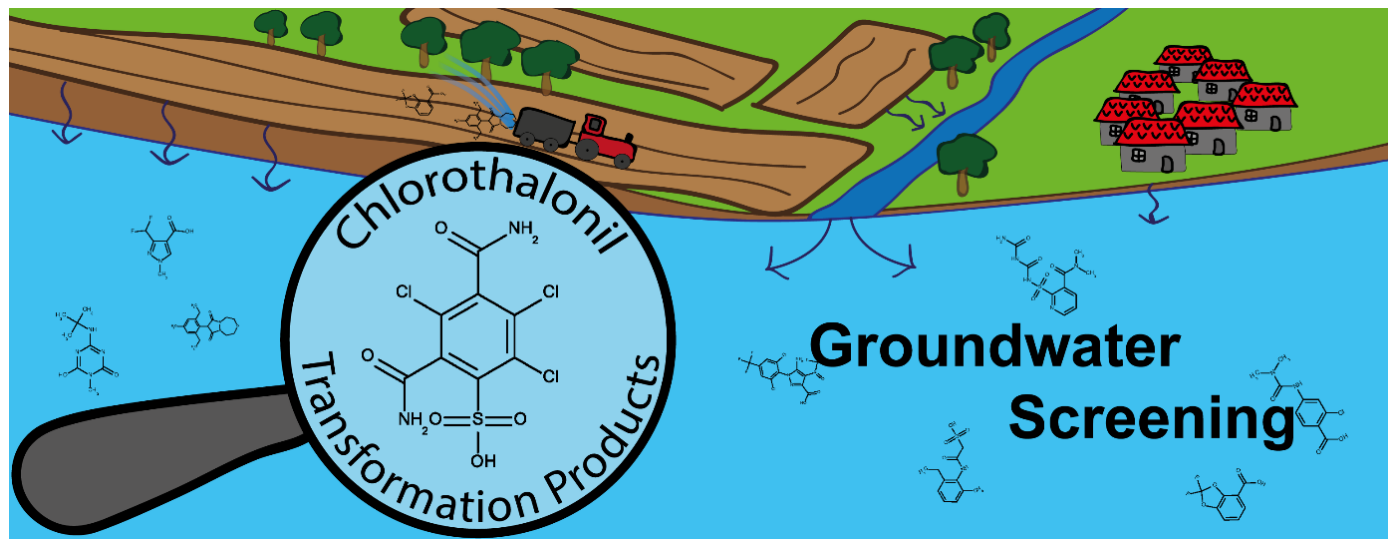

This document is the accepted manuscript version of the following article:

Kiefer, K., Müller, A., Singer, H., Hollender, J., New relevant pesticide transformation products in groundwater detected using target and suspect screening for agricultural and urban micropollutants with LC-HRMS, Water Research (2019), doi: https://doi.org/10.1016/j.watres.2019.114972.

This manuscript version is made available under the CC-BY-NC-ND 4.0 license http://creativecommons.org/licenses/by-nc-nd/4.0/ 


\section{Abstract}

Groundwater is a major drinking water resource, but its quality is threatened by a broad variety of anthropogenic micropollutants (MPs), originating from agriculture, industry, or households, and undergoing various transformation processes during subsurface passage. To determine a worst-case impact of pesticide application in agriculture on groundwater quality, a target and suspect screening for more than 300 pesticides and more than 1100 pesticide transformation products (TPs) was performed in 31 Swiss groundwater samples which predominantly originated from areas with intensive agriculture. To assess additional urban contamination sources, more than 250 common urban MPs were quantified. Most of the screened pesticide TPs were experimentally observed by the pesticide producers within the European pesticide registration. To cover very polar pesticide TPs, vacuum-assisted evaporative concentration was used for enrichment, followed by liquid chromatography high-resolution tandem mass spectrometry (LC-HRMS/MS). Based on intensity, isotope pattern, retention time, and in silico fragmentation, the suspect hits were prioritised and verified. We identified 22 suspects unequivocally and five tentatively; 13 TPs are reported here for the first time to be detected in groundwater. In 13 out of 31 groundwater samples, the total concentration of the 20 identified and quantified suspects ( 1 pesticide and 19 pesticide TPs) exceeded the total concentration of the 519 targets (236 pesticides and TPs; 283 urban MPs) for which we screened. Pesticide TPs had higher concentrations than the parent pesticides, illustrating their importance for groundwater quality. The newly identified very polar chlorothalonil TP R471811 was the only compound detected in all samples with concentrations ranging from 3 to $2700 \mathrm{ng} / \mathrm{L}$. Agricultural MP concentration and detection frequency correlated with agricultural land use in the catchment, except for aquifers, where protective top layers reduced MP transport from the surface. In contrast to agricultural MPs, urban MPs displayed almost no correlation with land use. The dominating entry pathway of urban MPs was river bank filtration.

Keywords: pesticides metabolites; high resolution mass spectrometry; MetFrag; micropollutants; monitoring; land use

\section{Introduction}

Groundwater is in many countries the major source for drinking water; in Switzerland, $80 \%$ of drinking water originates from groundwater (Freiburghaus 2012). However, especially in densely populated areas, human activities threaten groundwater quality. Pharmaceuticals, sweeteners, or industrial chemicals (here referred to as urban MPs) are predominantly released to the aquatic environment via wastewater (Daughton and Ternes 1999), and consequently may enter groundwater along wastewater impacted streams (Heberer et al. 2004, Lewandowski et al. 2011) or leaky sewers (Wolf et al. 2012). Agricultural MPs, such as pesticides and their TPs, are intentionally spread into the environment and reach groundwater mainly via seepage from agricultural soils (Postigo and Barcelo 2015).

During subsurface passage, MPs may undergo natural attenuation processes such as sorption or degradation (Lapworth et al. 2012, Postigo and Barcelo 2015). However, the TPs formed are often more persistent and more mobile than the parent compound, as shown for several pesticides (Buttiglieri et al. 2009, Kolpin et al. 2004). Reemtsma et al. (2016) and Arp et al. (2017) highlighted the risks that so-called PMOCs (persistent and mobile organic contaminants) pose to drinking water supplies. PMOCs easily migrate in the water cycle, reach water works, and may even pass through 
more advanced technologies such as activated carbon filtration or ozonation. Shallow aquifers with well-permeable top layers and interactions with surface waters are highly vulnerable to contamination with polar and persistent MPs. Due to the lack of appropriate analytical methods, Reemtsma et al. (2016) expect that most PMOCs have been so far overlooked.

While many urban MPs so far are not considered in Swiss and European drinking water regulation, a drinking water limit of $100 \mathrm{ng} / \mathrm{L}$ applies to pesticides and their relevant TPs (EDI 2016, European Commission 1998). Pesticide TPs are defined as relevant if they either i) still exhibit pesticidal activity, ii) show severe toxicological effects (European Commission 2003), or iii) if their toxicity is unknown but the parent is considered to be toxic. The relevance is only classified if the pesticide TPs are predicted to exceed $100 \mathrm{ng} / \mathrm{L}$ after $1 \mathrm{~m}$ soil passage. So far, pesticide TPs are insufficiently monitored for three reasons: i) reference material for TPs is often not available, ii) analytical methods are not appropriate, and iii) many pesticide TPs are not known because pesticide registration data is either not easily accessible or not at all available. Currently available pesticide TP lists (Banning et al. 2019, Reemtsma et al. 2013b) represent the result of a prioritization process, meaning that the lists are possibly not comprehensive. The insufficient monitoring is especially concerning as pesticide TPs often occur more frequently and at higher concentrations than the active substance, as was reported e.g. for acetochlor, alachlor, metolachlor and chloridazon (Buttiglieri et al. 2009, FOEN 2019, Kolpin et al. 2004, Kolpin et al. 1998, Weber et al. 2007).

Reemtsma et al. (2013a) addressed this data gap with a target screening for 150 pesticide TPs in German surface and groundwater with triple-quadrupole mass spectrometry and detected 17 so far unpublished pesticide TPs. However, the 150 pesticide TPs were selected based on expert judgement about their occurrence in the aquatic environment, availability of reference material, toxcicological assessment, and their ability to be analysed with the chosen method. Some pesticide TPs, which were already known to be widespread in the environment (e.g. chloridazon-desphenyl, N,Ndimethylsulfamide) could not be included due to their polarity (Reemtsma et al. 2013b).

To overcome the lack of reference material, high resolution mass spectrometry followed by a suspect screening approach has in recent years been successfully used in environmental analytics (Brunner et al. 2019, Kern et al. 2009, Moschet et al. 2013). Briefly, HRMS data is searched against the suspect list containing the monoisotopic masses of expected compounds. Then, the suspect hits are checked for plausibility. For this, different criteria have been applied: i) absence / low intensity in background, ii) retention time (RT), iii) isotope pattern, iv) ionization potential, and v) MS/MS fragmentation. Measured MS/MS fragments may be used to search MS/MS libraries such as the European MassBank (Horai et al. 2010), MassBank of North America (MoNA 2019) and METLIN (Smith et al. 2005), to predict molecular fingerprints or to compare with predicted fragments by applying in silico tools such as CSI:FingerID (Duhrkop et al. 2015) and MetFrag (Ruttkies et al. 2016). However, certainty in the true identity of a suspect hit can only be obtained with reference material.

This study aimed to comprehensively assess the impact of pesticide application in agriculture on groundwater quality. Therefore, we applied a target and suspect screening approach to cover more than 300 pesticides and more than 1100 TPs. Most TPs were experimentally observed by the pesticide producers within the European pesticide registration. The analytical method was optimised for very polar compounds using vacuum-assisted evaporative concentration as enrichment method. To ensure that as many pesticide TPs as possible were detected, 21 groundwater monitoring sites were chosen which were known to be polluted with several pesticides or known TPs. In addition, ten 
groundwater monitoring sites were sampled which were more influenced by urban MPs or relatively pristine, to investigate how widespread the occurrence of pesticide TPs is in groundwater. To compare the contamination from agriculture to the overall contamination with MPs in the investigated groundwater monitoring sites, we analyzed additionally more than $250 \mathrm{MPs}$ known to originate from urban sources. The MP pattern was then compared to land use and hydrogeological settings.

\section{Methods}

\subsection{Groundwater Samples}

The 31 groundwater samples originated from nine springs and 22 abstraction wells (referred to as monitoring sites) regularly monitored within the Swiss National Groundwater Monitoring NAQUA, operated by the Federal Office for the Environment in close collaboration with the cantonal authorities (https://www.bafu.admin.ch/bafu/en/home/topics/water/info-specialists/state-ofwaterbodies/state-of-groundwater.html). The data presented shows rather a worst-case scenario, and therefore, is not representative of Swiss groundwater quality.

The monitoring sites were selected based on the land use in the catchments and long-term monitoring data: i) 21 monitoring sites showed high concentrations or frequent detections of pesticides or their TPs in the past, or their catchment was dominated by agriculture; ii) seven monitoring sites were impaired by wastewater tracers such as acesulfame, benzotriazole, carbamazepine and sulfamethoxazole; and iii) three monitoring sites were relatively pristine with regards to MP concentrations and/or anthropogenic activities in their catchments. For each monitoring site, the catchment was estimated based on abstraction volume / spring discharge, hydrogeological maps and reports on the designation of groundwater protection zones. The sodefined catchments were then compared to land-use statistics. Land use classes were as follows: i) agriculture (cropland, orchards, vineyards), ii) settlement (settlement, transport infrastructure), and iii) grassland/forest/other (summer pastures, grazing and livestock, forest, unproductive areas). This data set on the land use, size and location of the catchments was provided by the Swiss Federal Office for the Environment.

\subsection{Sampling}

Groundwater samples were collected in May 2017 within the routine sampling of NAQUA. The samples were filled in laboratory glass bottles (which were previously annealed at $500{ }^{\circ} \mathrm{C} ; 500 \mathrm{~mL}$ and $1000 \mathrm{~mL}$ bottles, SIMAX Kavalier, Czech Republic), stored for up to one week at $<10^{\circ} \mathrm{C}$ in the dark, and then kept frozen at $-20^{\circ} \mathrm{C}$ until measurement. To assess possible contamination from sample handling, ultrapure water was analogously frozen, enriched and analysed as blank samples.

\subsection{Sample Enrichment}

To avoid the loss of very polar compounds during enrichment, the samples were concentrated via vacuum-assisted evaporative concentration using the Syncore ${ }^{\circledR}$ Analyst (BÜCHI, Switzerland) with slight modifications to the method validated by Mechelke et al. (2019): $60 \mathrm{~mL}$ sample volume was filled into BÜCHI glass vials $(0.3 \mathrm{~mL}$ appendix volume), spiked with 224 isotope labelled internal standards (ILIS) and evaporated at $20 \mathrm{mbar}$ and $45^{\circ} \mathrm{C}$ to $1-5 \mathrm{~mL}$ using the back-flush unit. The BÜCHI glass vials were rinsed with $1.5 \mathrm{~mL} \mathrm{H} \mathrm{H}_{2} \mathrm{O}$ /methanol mix (85:15) to reduce analyte losses by sorption on the glass surface. Then, the samples were evaporated to $\sim 0.3 \mathrm{~mL}$, the sample volume was adjusted to 
$0.4 \mathrm{~mL}$ with ultrapure water, and centrifuged at $10621 \mathrm{~g}$ for five minutes in flat bottom glass inserts (0.5 mL, 110506, BGB Analytik AG, Switzerland). The supernatant was transferred using glass Pasteur pipettes (747715, Brand GmbH, Germany) to HPLC vials (1.5 mL vials: $080400-\mathrm{XL}$; screw caps: 090301; BGB Analytik, Switzerland) equipped with conical glass inserts $(0.34 \mathrm{~mL}, 110503, \mathrm{BGB}$ Analytik AG, Switzerland), kept at $8{ }^{\circ} \mathrm{C}$ and analysed within 4 days.

For target quantification and quality control, 22 calibration standards ranging from $0.1-1000 \mathrm{ng} / \mathrm{L}$, six

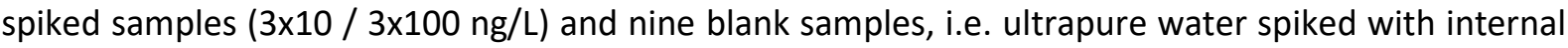
standards, were enriched and analysed analogously to the samples (SI-A1).

\subsection{LC-HRMS/MS}

A volume of $100 \mu \mathrm{L}$, corresponding to $15 \mathrm{~mL}$ of the original water sample, was injected on a reverse phase C18 column (Atlantis ${ }^{\circledR}$ T3 $3 \mu \mathrm{m}, 3.0 \times 150 \mathrm{~mm}$; Waters, Ireland) which retains polar compounds well. To improve the retardation of very polar compounds, the gradient started with $100 \%$ eluent $A$ (water $+0.1 \%$ concentrated formic acid), then eluent $B$ (methanol $+0.1 \%$ concentrated formic acid) was increased from 1.5 to $18.5 \mathrm{~min}$ to $95 \%$, held for $10 \mathrm{~min}$, and lowered again to the starting conditions. The column was re-equilibrated for $4 \mathrm{~min}$. The flow rate was $0.3 \mathrm{~mL} / \mathrm{min}$. The HPLC system comprised a PAL autosampler (CTC Analytics, Switzerland) and a Dionex UltiMate3000 RS pump (Thermo Fisher Scientific, U.S.).

Samples were measured (in sequence) first in positive, then in negative electrospray ionization mode on a high-resolution mass spectrometer (Q Exactive Plus, Thermo Fisher Scientific, U.S.). After ionization with electrospray (spray voltage 4/-3 kV), an MS1 full-scan (m/z 100-1000, mass resolution 140000 at $\mathrm{m} / \mathrm{z}$ 200) was performed followed by five data-dependent fragmentation experiments (mass resolution 17500 at m/z 200) using higher energy collision-induced dissociation (HCD). MS/MS acquisition was triggered by the $\mathrm{m} / \mathrm{z}$ of the target ions with normalised collision energies (NCE) 15120 depending on the $\mathrm{m} / \mathrm{z}$. Isolation window was $1 \mathrm{Da}$. If no target ion was detected, the most intense ions in the MS1 were fragmented at NCE 15, 60, and 105 (further details in SI-A1). To confirm suspects with reference material, samples were re-measured with adjusted MS/MS settings (section 2.6.4 and SI-A 4).

\subsection{Target Screening}

TraceFinder 4.1 (Thermo Fisher Scientific, U.S.) was used for quantification of 519 target analytes with an extraction window of $5 \mathrm{ppm}$. The RT and MS/MS fragments of the target analytes (SI-B 4) were compared to RT and fragments of reference material. Most analytes were quantified with a linear calibration curve (weighting $1 / \mathrm{x}$ ) using the peak area ratio of analyte and ILIS. If a structurally identical ILIS was not available (70\% of targets), data was exported to R (R Core Team 2016) and an in-house

script (https://github.com/dutchjes/TFAnalyzeR/blob/master/RelativeRecoveryCalculation.R) was used to select the ILIS which eluted at similar RT as the analyte and which resulted in the best relative recovery (close to $100 \%$ in all spiked samples, SI-B 4). For compounds without structurally identical ILIS, concentrations were corrected by the relative recovery (for details see SI-A 2). 


\subsection{Suspect Screening}

\subsubsection{Suspect List}

We aimed to screen for all organic molecules and their TPs which were registered as pesticides (active substances, safeners, synergists) in Switzerland from 2005 to 2017 according to the Ordinance on Plant Protection Products; pesticides only registered according to the Ordinance on Biocidal Products were not included. Pesticides with undefined composition such as natural mixtures (e.g. essential oils) or technical products (e.g. alkyl-dimethyl-benzyl-ammoniumchloride) were excluded from the screening or replaced by representative molecules. As groundwater may be polluted by compounds applied decades ago, eight pesticides, only approved before 2005 but sold in high amounts, were additionally included in the screening. In total, the pesticide list comprised 396 organic molecules. A list of 1120 TPs, covering $74 \%$ of these pesticides, was collected from different sources, such as Latino et al. (2017), Lewis et al. (2016), Reemtsma et al. (2013b), BLW (2019), Agroscope (personal communication) or in-house data. The majority of the TPs $(85 \%)$ originated from the database Eawag-Soil (www.envipath.org/package) containing pesticide transformation pathways assessed in aerobic laboratory soil experiments by the pesticide producers within the European registration process (Latino et al. 2017). Of the pesticides for which no transformation data could be gathered, $23 \%$ were pheromones or phytoregulators, and $33 \%$ were sold in low amounts $(<1 \mathrm{t} / \mathrm{a})$, and therefore, their TPs were expected to be less important. For $5 \%$ of pesticides without transformation data, sales volumes ranged from 1-10 t/a, and for $39 \%$ sales data was not available. Refer to SI-B 1 and SI-B 2 for a list of pesticides and TPs. Finally, the suspect list contained 223 pesticides and 1033 TPs, which were not yet covered by the target screening applied (section 2.5) and had a monoisotopic mass $>99$ Da (Figure 1).

\subsubsection{Automated Screening}

Automated screening with Compound Discoverer 2.1 (CD 2.1; Thermo Fisher Scientific, U.S.) included a peak picking step, RT alignment, and grouping of isotopologues and adducts (to form compounds) as well as grouping of compounds across samples (Figure 1). Compounds were marked as background if their peak area in the samples was less than three times larger than the maximum peak area in the blanks. Suspects were annotated based on the exact mass, and targets using exact mass and RT with a RT window of 2 min. Parameter settings were optimised and tested with ILIS data (Figure SI-A 2); ILIS detection rate was 97\%. See Table SI-A 2 for details on parameter settings.

\subsubsection{Suspect Filtering and Prioritization}

As the parameters were set to avoid false negative detections, most suspect hits represented noise compounds that could not be removed automatically with CD 2.1. Therefore, compounds annotated as suspects were checked visually and excluded if the signal to noise $(\mathrm{S} / \mathrm{N})$ was below 10 . Suspect hits which were likely a false positive were excluded using the following criteria: i) peak height $\left\langle 10^{5}\right.$, ii) unrealistic RT based on predicted hydrophobicity (SI-A 3), iii) missing $\mathrm{Cl} / \mathrm{Br}$ isotopologue although expected due to molecular formula and detection limit estimated by CD 2.1, iv) very noisy extracted ion chromatogram (EIC), v) no MS/MS fragment explained by the structure using the in silico fragmenter MetFrag (Ruttkies et al. 2016) if MS/MS scans were acquired (46\% of suspect hits with $\mathrm{S} / \mathrm{N}>10$ ). MetFrag $\mathrm{CL} 2.4 .2$ was run in an automated way for all suspect hits using an $\mathrm{R}$ script. MetFrag retrieved candidate structures from the suspect list (SI-B 1, SI-B 2) and the web database ChemSpider (RSC 2018), and compared the predicted fragments of each candidate with the measured one (SI-A 3). Then, reference material was obtained either commercially or via the 
European Crop Protection Agency (ECPA) for the most promising suspect hits according to MetFrag results, peak shape and intensity, plausibility of RT and mass accuracy.

\subsubsection{Suspect Confirmation and Quantification}

To confirm the suspects, seven samples were re-measured with adjusted MS/MS settings (SI-A 4). The MS/MS fragments $(\mathrm{m} / \mathrm{z}$, intensity) and RT of the suspect hit were compared to the MS/MS fragments and RT of reference material by plotting EICs and head to tail plots using the R packages MSnbase (Gatto and Lilley 2012) and MSMSsim (Schollée 2017). Refer to SI-A 4 for details on the R script and to SI-C for the resulting plots. Then, the identification confidence was classified following the scheme in Schymanski et al. (2014).

The confirmed suspects were quantified in the 31 samples by applying the calibration model determined later with the same LC-HRMS/MS system. For quantification, seven samples were enriched and analysed again, together with twelve calibration standards and three spiked samples. Then the confirmed suspects were quantified in the 31 measurement files from the first analysis and the seven measurement files from the second analysis, using the calibration standards from the second analysis (section 2.5 and SI-A 4). In case of three suspect hits, reference material could only be obtained for their isomer or structurally similar TP, so that concentrations were estimated assuming the same ionization efficiency as their isomer or structurally similar TP.

Data analysis was performed in RStudio with R version 3.4.1 (R Core Team 2016) if not stated otherwise. The HRMS measurement data files were converted to the open .mzXML data format using the msconvert tool from ProteoWizard (Chambers et al. 2012). JChem for Office (Version 17.1.2300.1455; ChemAxon Ltd.) was used for chemical structure illustration and logD prediction. The $90^{\text {th }}$ percentiles of concentrations were reported if more than $10 \%$ of the samples showed a detection.

\section{Results and Discussion}

\subsection{Target Screening}

The LOQ was $\leq 10 \mathrm{ng} / \mathrm{L}$ for $78 \%$ of the 519 targets, including more than 100 very polar compounds with $\log \mathrm{D}_{\mathrm{pH}}$ ranging from -5 to 0 , showing the excellent sensitivity and broad applicability of the analytical setup comprised of vacuum-assisted evaporation followed by LC-HRMS/MS analysis. In the 31 groundwater samples, we detected 33 of 169 pesticides, 30 of 67 pesticide TPs and 42 of 283 urban MPs (16 of 175 pharmaceuticals, seven of 46 pharmaceutical TPs, one of seven industrial chemicals, three of five sweeteners and 15 of 50 others). Individual samples contained four to 44 targets (

Figure 4, SI-B 4). Two pesticides (atrazine, bentazone) and one relevant pesticide TP (atrazinedesethyl) exceeded the European / Swiss drinking water limit for pesticides and relevant pesticide TPs of $100 \mathrm{ng} / \mathrm{L}$. For comparison, one pesticide TP with unclear relevance, four non-relevant pesticide TPs, one non-relevant biocide TP and five urban MPs also exceeded $100 \mathrm{ng} / \mathrm{L}$ (without regulatory consequences, Table SI-A 3). The herbicide TP chloridazon-desphenyl showed the highest concentration (1800 $\mathrm{ng} / \mathrm{L}$ ) followed by another herbicide TP, metolachlor-ESA with $970 \mathrm{ng} / \mathrm{L}$. Both TPs have been known to be widespread in groundwater for more than 10 years (Buttiglieri et al. 2009, Kolpin et al. 1998, Loos et al. 2010, Weber et al. 2007), and therefore are part of many routine monitoring programmes. 


\subsection{Suspect Screening}

\subsubsection{Suspect List}

The suspect list comprised 223 pesticides and 1033 TPs with a monoisotopic mass >99 Da; most pesticide TPs were observed in aerobic soil degradation experiments or in lysimeter and field studies by the pesticide producers within the European pesticide registration. In order to minimize false negative findings, the suspect list was not reduced beforehand by evaluating the suspects' likelihood of being present in groundwater (polarity, sales volume), of being retained by LC method (polarity) or ionized in electrospray (presence of functional groups). Nevertheless, their amenability to LCelectrospray-MS was evaluated: more than $95 \%$ have a similar polarity as the analytes quantified with the applied analytical method (Figure 1) and $99.5 \%$ contain a heteroatom, increasing the electrospray ionization potential (Figure SI-A 1).

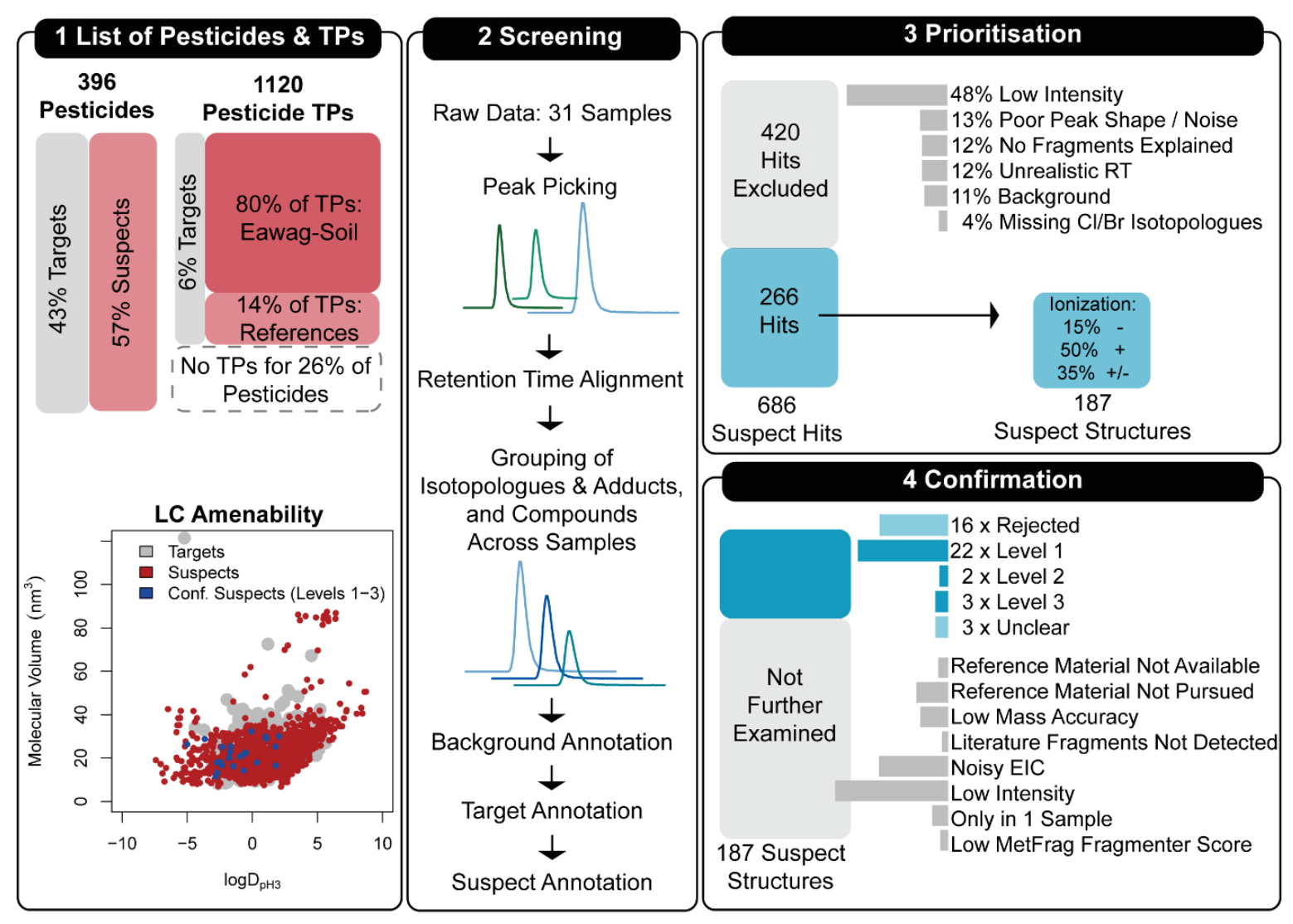

Figure 1: The compiled list of pesticides and TPs comprised 396 pesticides (43\% targets, $57 \%$ suspects) and 1120 TPs (6\% targets, 94\% suspects). 1256 suspects (223 pesticides, 1033 TPs) had a monoisotopic mass >99 Da; $95 \%$ of these suspects had a similar logD as the target compounds and $99.5 \%$ included a heteroatom (box 1). After the automated screening (box 2), the suspect hits were prioritised (box 3 , blue color) and the most promising suspects were further examined with reference material if available (box 4 , blue color).

\subsubsection{Prioritisation and Identification}

After background, target and noise removal, 686 suspect hits, annotated with 430 suspect structures, remained. The 686 suspect hits were reduced to 266 by excluding hits with low intensity (48\%), poor peak shape / noise (13\%), no MS/MS fragments explained by the suspect according to the in silico fragmenter MetFrag (12\%), unrealistic RT (12\%), background (11\%), or missing $\mathrm{Cl} / \mathrm{Br}$ isotopologues if expected from the formula (4\%). The 266 suspect hits corresponded to only 187 different suspect structures as some compounds were grouped insufficiently across samples, even though $\mathrm{m} / \mathrm{z}$ and RT 
deviated only slightly; others were detected in positive and negative ionization mode or the EICS exhibited several peaks with different RTs. The 187 suspect structures were then further prioritised by taking e.g. peak intensity and shape, detection frequency, mass accuracy and MetFrag results into account (Figure 1, SI-B 3).

Reference material could be obtained for the 43 most promising suspects, either commercially (twelve reference standards) or from the pesticide producers via the European Crop Protection Agency (31 reference standards). For details on suspects which were not further investigated, see SIA 3 and SI-B 3. We confirmed 21 TPs and one pesticide (Level 1) and rejected nine TPs and seven pesticides. Two TPs were identified as probable (Level 2, no reference standard), three TPs as tentative structure (Level 3), either because reference material was not available (2 TPs) or due to analytical problems (1 TP, reference material impure or unstable), and three suspects remained unclear (details in SI-C) and could not be classified following Schymanski et al. (2014), although reference material was available (Figure 1). The confirmed suspect hits (Levels 1-3, Table 1) included among others TPs from the fungicides chlorothalonil (7 TPs), fluxapyroxad / bixafen (2 TPs), metalaxyl (1 TP), and fludioxonil (1 TP), TPs from the herbicides terbuthylazine (4 TPs), dimethachlor (1 TP), acetochlor / metolachlor (2 TPs), nicosulfuron (2 TPs), and TPs from the insecticide fipronil (2 TPs). 13 TPs (Level 1: 10; Level 2: 1, Level 3: 2) are reported here for the first time in groundwater. SI-B 5 and SI-C provide detailed information for each confirmed or rejected suspect. MS/MS spectra of the confirmed suspects were uploaded to the European MassBank (Horai et al. 2010).

Confirmed suspects tended to have higher peak intensity than rejected suspects (Figure SI-A 4a; median intensity $3.5 \times 10^{5}$ vs. $5 \times 10^{4}$ ). This difference was expected since intense peaks provide more information about the candidate, and therefore, facilitate the correct evaluation of the suspect hit before confirmation with reference material. Interestingly, sales data was not a strong indicator for the likelihood of a positive suspect hit (Figure SI-A 4c).

In silico fragmentation was especially useful for the correct prioritization of intense peaks with relatively large $\mathrm{m} / \mathrm{z}$ (>300), such as in the cases of chlorothalonil and fipronil TPs. Intense precursor peaks improve the quality of MS/MS spectra, showing less interfering peaks, and the larger molecules may produce more information-rich spectra. Conversely, if precursor intensity is low, as is the case for many suspect hits, acquiring meaningful MS/MS spectra is challenging because the high number of interfering peaks leads to many fragments that are not related to the compound of interest. For example, for one compound $83 \mathrm{MS} / \mathrm{MS}$ peaks were detected, of which 26 could be explained by the annotated suspect fenazaquin (Figure SI-A 5). For this suspect, 2122 candidates were retrieved from ChemSpider, and, up to 47 fragments could be explained by ChemSpider hits. The suspect fenazaquin was then rejected with reference material due to different retention time.

Using broad suspect lists or even web databases such as ChemSpider for compound elucidation proves often to be less successful for TP identification compared to high quality suspect lists. In our case, 13 out of the confirmed suspects (Levels 1-3) were not part of ChemSpider, while ten were in Chemspider but based on expert knowledge were not expected to originate from pesticides, based on their names. Compounds that cannot be traced back to specific sources are less likely to be prioritized for elucidation in suspect and non-target screenings. This highlights the need for high quality suspect lists, comprising e.g. experimentally observed TPs as in this study, to increase the number of identifications of compounds that are so far not known to be of environmental relevance. 
Table 1: Confirmed pesticide TPs (Levels 1-3) except for Level 3 candidates with analytical problems (cymoxanyl TPs: reference material impure / unstable) ordered according to novelty and spread. TP names from European pesticide registration. Ident. Level $=$ Identification Level; $L O Q=$ limit of quantification; $c 90$ th $=90^{\text {th }}$ percentile of concentrations; $\mathrm{C}_{\max }=$ maximum concentration .

\begin{tabular}{|c|c|c|c|c|c|c|}
\hline Reported in Groundwater for the First Time & $\begin{array}{l}\text { Ident. } \\
\text { Level }\end{array}$ & $\log D_{\mathrm{pH} 7}$ & $\begin{array}{l}\text { LOQ } \\
\text { (ng/L) }\end{array}$ & $\begin{array}{c}\text { Detections } \\
\text { (31 Samples) }\end{array}$ & $\begin{array}{c}\mathrm{C}_{90 \mathrm{th}} \\
\text { (ng/L) }\end{array}$ & $\begin{array}{c}\mathrm{C}_{\max } \\
\text { (ng/L) }\end{array}$ \\
\hline Chlorothalonil TP R471811 & 1 & -1.7 & 3 & 31 & 1100 & 2700 \\
\hline Terbuthylazine TP CSCD692760 & 1 & -1.5 & 3 & 27 & 27 & 32 \\
\hline Terbuthylazine TP CSAA036479 & 1 & -2.7 & 0.6 & 25 & 6.4 & 27 \\
\hline Chlorothalonil TP R417888 Isomers & 3 & -0.7 & - & $18 / 19$ & $\sim 18 / \sim 39$ & $\sim 49 / \sim 120$ \\
\hline Chlorothalonil TP R419492 & 1 & -4.5 & - & 18 & \multicolumn{2}{|c|}{ Not Quantified } \\
\hline Chlorothalonil TP SYN548580 & 1 & 0.0 & - & 13 & \multicolumn{2}{|c|}{ Not Quantified } \\
\hline Chlorothalonil TP SYN507900 & 1 & 0.4 & 1.3 & 13 & 33 & 150 \\
\hline Fipronil TP RPA 106681 & $2 b$ & 1.0 & - & 11 & $\sim 14$ & $\sim 120$ \\
\hline Fipronil TP RPA 200761 & 1 & 1.1 & 1 & 6 & 6.6 & 71 \\
\hline Fluxapyroxad \& Bixafen TP CSCD465008 & 1 & -2.8 & 15 & 1 & - & $\sim 60$ \\
\hline Fluxapyroxad \& BixafenTP CSAA798670 & 1 & -2.7 & 10 & 1 & - & 13 \\
\hline Cycloxydim TP BH 517-TSO E/Z isomer* & 1 & -0.1 & 1.3 & 1 & - & 1.3 \\
\hline \multicolumn{7}{|l|}{ Rarely Mentioned in Literature } \\
\hline $\begin{array}{l}\text { Terbuthylazine TP CSCD648241 } \\
\text { Valsecchi et al. (2017), LfU (2018) }\end{array}$ & 1 & -2.5 & 0.5 & 29 & 54 & 190 \\
\hline $\begin{array}{l}\text { Terbuthylazine TP MT23/GS16984 } \\
\text { Valsecchi et al. (2017), LfU (2018) }\end{array}$ & 1 & 1.8 & 0.5 & 29 & 52 & 78 \\
\hline $\begin{array}{l}\text { Chlorothalonil TP R417888 } \\
\text { LUBW (2011) }\end{array}$ & 1 & -0.7 & 1 & 28 & 470 & 1300 \\
\hline $\begin{array}{l}\text { Dimethachlor TP CGA } 369873 \\
\text { Reemtsma et al. (2013a) }\end{array}$ & 1 & -0.9 & 0.5 & 28 & 67 & 95 \\
\hline $\begin{array}{l}\text { Nicosulfuron TP UCSN } \\
\text { Steverkooperation (2016) }\end{array}$ & 1 & -2.3 & 0.2 & 27 & 24 & 75 \\
\hline $\begin{array}{l}\text { Metolachlor TP NOA413173 } \\
\text { Reemtsma et al. (2013a) }\end{array}$ & 1 & -3.6 & 1.7 & 22 & 130 & 430 \\
\hline $\begin{array}{l}\text { Metolachlor TP CGA } 368208 \text { / Acetochlor } \\
\text { sulfonic acid Reemtsma et al. (2013a) }\end{array}$ & 1 & -0.5 & 1 & 20 & 46 & 150 \\
\hline $\begin{array}{l}\text { Nicosulfuron TP AUSN } \\
\text { Steverkooperation (2016) }\end{array}$ & 1 & -1.6 & 3 & 17 & 27 & 47 \\
\hline $\begin{array}{l}\text { Chlorotoluron TP CGA15140 } \\
\text { Reemtsma et al. (2013a) }\end{array}$ & $2 a$ & -1.8 & - & 9 & \multicolumn{2}{|c|}{ No Standard } \\
\hline $\begin{array}{l}\text { Pinoxaden TP NOA 407854* } \\
\text { Reemtsma et al. (2013a) }\end{array}$ & 1 & 2.1 & 0.3 & 4 & 0.3 & 5.5 \\
\hline $\begin{array}{l}\text { Fludioxonil TP CGA } 192155 \\
\text { Reemtsma et al. (2013a) }\end{array}$ & 1 & -0.7 & 3 & 2 & - & 200 \\
\hline $\begin{array}{l}\text { Metalaxyl-M TP CGA108906 } \\
\text { Reemtsma et al. (2013a) }\end{array}$ & 1 & -5.0 & 7 & 1 & - & 8.8 \\
\hline
\end{tabular}




\subsection{New Pesticide TPs}

Within the suspect screening, one pesticide (oxadixyl) and 26 pesticide TPs (Levels 1-3) were identified. Table 1 presents the confirmed TPs, except for Level 3 candidates with analytical problems (cymoxanil TPS). For details, see SI-B 5 and SI-C. The most prominent pesticide TPs regarding their novelty, concentration, or spread are discussed in the following section.

\subsubsection{Chlorothalonil TPs}

To the best of our knowledge, we report here the detection of the chlorothalonil TP R471811 for the first time in environmental samples. TP R471811 was the only MP detected in all samples, exceeding $100 \mathrm{ng} / \mathrm{L}$ in 20 out of 31 samples. Additionally, this compound had the highest maximum concentration of all compounds, detected at $2700 \mathrm{ng} / \mathrm{L}$ in a single sample (average in all samples 520 $\mathrm{ng} / \mathrm{L}, 90^{\text {th }}$ percentile $\mathrm{C}_{90 \mathrm{th}} 1100 \mathrm{ng} / \mathrm{L}$ ). In future, concentrations of R471811 might still increase due to its high persistence ( $\mathrm{DT}_{50}$ : $98-1000 \mathrm{~d}$ ) and further formation from the parent TP R417888 (Figure 2), whereby the removal of R471811 in drinking water production may prove challenging. Due to the high polarity and the electron-withdrawing functional groups, even more advanced treatment technologies such as activated carbon and ozonation are expected to hardly retain or degrade the compound (Matsushita et al. 2018, Von Sonntag and Von Gunten 2012). This is especially concerning because the toxicological relevance of the TPs has not been sufficiently assessed; however, the active substance is classified as carcinogenic, as reported within the current re-approval process in the EU (EFSA 2018). Therefore, TP R471811 should provisionally be classified as relevant (EFSA 2018) implying a drinking water limit of $100 \mathrm{ng} / \mathrm{L}$ (EDI 2016, European Commission 1998).

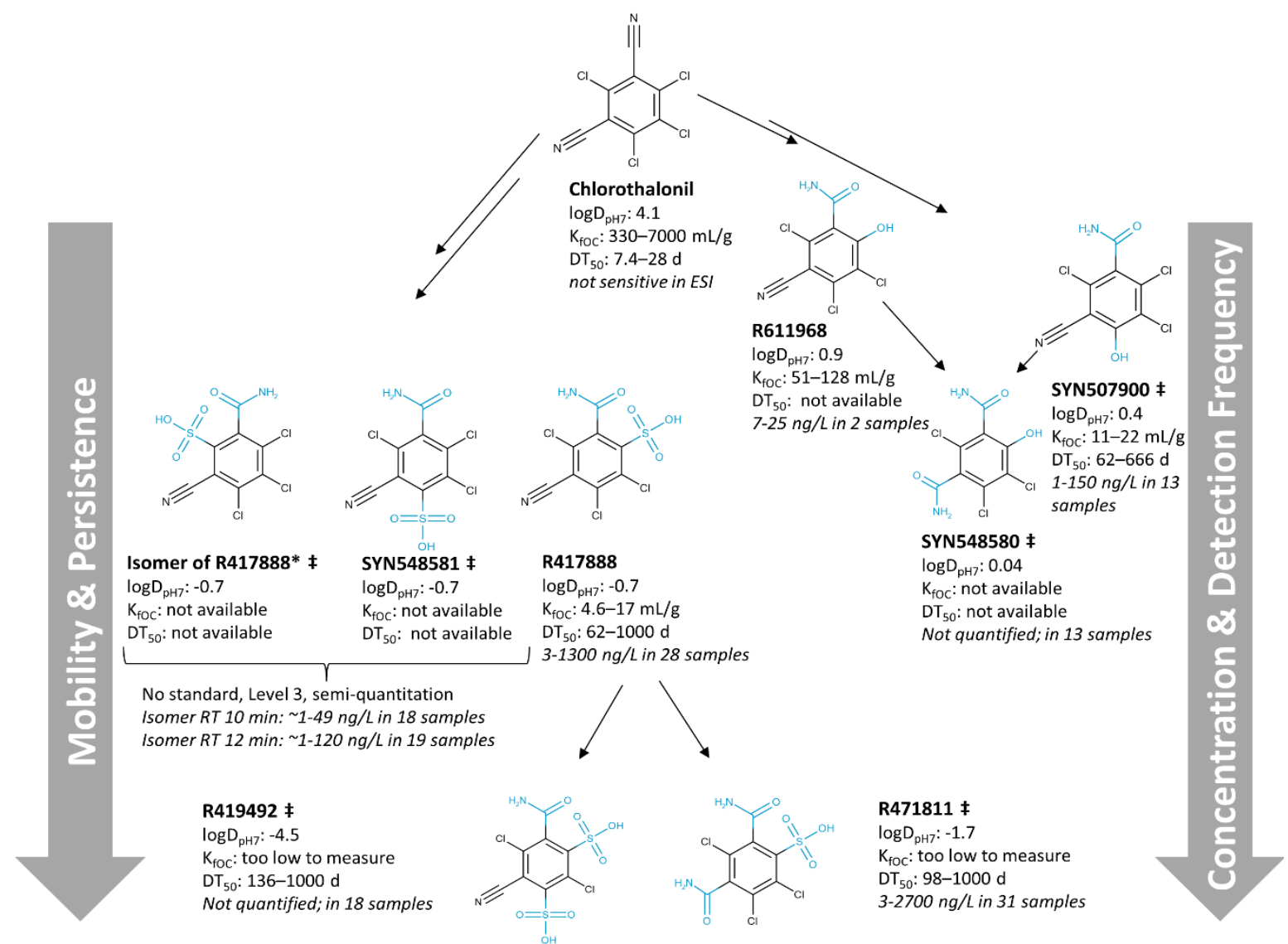

Figure 2: Chlorothalonil and its TPs detected in groundwater; concentrations and frequency of detection increase with mobility and persistence. $\mathrm{K}_{\text {foc }}$ and DT 50 from EFSA (2018); *isomer is not included in EFSA (2018); $¥$ detection in groundwater is reported here for the first time. 
The classification as relevant pesticide TPs applies as well to the other chlorothalonil TPs detected in this study (Figure 2). Whereas monitoring data from Germany is available for TP R417888 (LUBW 2011), we present here as well the first detection of TP SYN507900 (Level 1) and of two isomers of R417888 (Level 3) in groundwater. Two more TPs were detected later by a manual exact mass screening, because a recent EFSA report (2018) noted that additional chlorothalonil TPs are expected in groundwater. Therefore, the exact masses of these suspects were manually screened for to avoid false negatives. For TP R419492 we detected a broad and early-eluting peak $\left([\mathrm{M}-\mathrm{H}]^{-} \&[\mathrm{M}-2 \mathrm{H}]^{2-}\right.$; RT 4$6 \mathrm{~min}$ ) in 18 samples. The CD 2.1 workflow also successfully picked features (defined by their $\mathrm{m} / \mathrm{z}$ and RT) but unsuccessfully merged these features into a compound. Another TP, SYN548580, was detected in 13 samples (RT $10 \mathrm{~min}$ ); this TP was not on the suspect list. As reference material was received later, both TPs (R419492 and SYN548580) could only be confirmed (Level 1) and quantified in new samples from the same or other sites. In these samples, both TPs showed lower concentrations than R471811.

The high concentrations and detection frequencies of chlorothalonil TPs is explained by their mobility and the broad application of the fungicide chlorothalonil, e.g. for grain and vegetable cultivation but also on non-agricultural land such as golf courses (BLW 2018a). Chlorothalonil was not analysed in this study as chlorothalonil does not sufficiently ionise in electrospray. However, in German groundwater samples with high concentrations of TP R417888 ( $C_{\max } 1700 \mathrm{ng} / \mathrm{L}$ ) chlorothalonil has never been detected (LUBW 2011) because chlorothalonil adsorbs strongly to soil particles (EFSA 2018). Recently, the EU banned chlorothalonil due to the carcinogenic properties of chlorothalonil, the risk to fish and amphibians and the expected groundwater contamination with TPs (European Commission 2019).

\subsubsection{Fipronil TPs}

The suspect screening provided four suspect hits for fipronil TPs: RPA 200761 (log $\left.D_{p H 7}: 1.1\right), R P A$ $106681\left(\log D_{\mathrm{pH}}: 1.0\right), \mathrm{MB} 46233\left(\log \mathrm{D}_{\mathrm{pH}}: 2.2\right)$ and RPA 105320 ( $\left.\log \mathrm{D}_{\mathrm{pH}}: 3.6\right)$, none of which has previously been reported to be detected in groundwater. RPA 200761 was confirmed with reference material ( 6 detections, 1-70 ng/L). For the remaining TPs, reference material could not be obtained. However, the reference material for RPA 200761 was not pure, i.e. further peaks were detected for the $[\mathrm{M}+\mathrm{H}]^{+}$and $[\mathrm{M}-\mathrm{H}]^{-}$of the other TPs, the RTs of which matched with the detections of other TPs in the samples. MS/MS data could be acquired for RPA 106681, most fragments were annotated with structure proposals (Figure SI-A 6) so that RPA 106681 was identified as probable structure (Level 2b). Semi-quantitative concentrations ranging from 0.7 to $120 \mathrm{ng} / \mathrm{L}\left(\mathrm{c}_{90 \mathrm{th}} \sim 14 \mathrm{ng} / \mathrm{L}\right.$ ) in 11 samples were estimated assuming the same ionization efficiency as for RPA 200761.

The detection of fipronil TPs is surprising, because it is expected that relatively low amounts of the insecticide have been released to the environment. The insecticide fipronil was sold in Switzerland for seed treatment from 2009 to 2011 in low amounts ( $<5$ t/a) (BLW 2018b), but is not approved anymore due to high toxicity to bees. In addition, fipronil has been used as biocide, but sales data is not available. Fipronil and its less mobile, but well-known, TPs fipronil-sulfide (MB 45950), fipronilsulfone (MB 46136) and fipronil-desulfinyle (MB 46513) were not detected, which may be related to the high LOQs $(10-50 \mathrm{ng} / \mathrm{L})$, to their low mobility $\left(\log \mathrm{D}_{\mathrm{pH}}\right.$ : $\left.>4\right)$, and to the low application amounts several years ago. 


\subsubsection{Terbuthylazine TPs}

In many European countries, the triazine herbicide terbuthylazine has replaced atrazine (Alvarez et al. 2016), which was banned in the EU in 2005 (2004/248/EC 2004) and in Switzerland in 2009. While terbuthylazine and its well-known and relevant TP terbuthylazine desethyl were only detected in 12 and 19 samples, respectively, at low concentrations ( $c_{90 t h} 5 / 6.1 \mathrm{ng} / \mathrm{L}, \mathrm{C}_{\max } 22 / 38 \mathrm{ng} / \mathrm{L}$ ), the suspect screening revealed four additional TPs: CSAA036479 (LM2), CSCD692760 (LM3), MT23 (LM5), and CSCD648241 (LM6). The four TPs were detected in 80 - 90\% of the samples with c9oth ranging from 6.4 to $54 \mathrm{ng} / \mathrm{L}$. While the TPS LM2 and LM3 were only reported in groundwater within field studies performed for the European pesticide registration (EFSA 2017), Valsecchi et al. (2017) and LfU (2018) detected LM5 and LM6 in an Italian aquifer and German drinking water, respectively.

\subsubsection{Nicosulfuron TPs}

We identified two non-relevant nicosulfuron TPs, UCSN and AUSN. The more persistent UCSN was measured more frequently and at higher concentrations than the less persistent AUSN (UCSN: DT 50 126-308 d, 27 detections, C90th 24 ng/L, C $\max 75$ ng/L; AUSN: DT 50 74-218 d, 17 detections, C90th 27 ng/L, $\left.\mathrm{C}_{\max } 47 \mathrm{ng} / \mathrm{L}\right)$ (EFSA 2008). Suspect hits for two other nicosulfuron TPs, MU-466 and HMUD, were not further examined with reference material due to very low peak intensity. In German surface waters, the TPs AUSN, UCSN and ASDM were detected at concentrations of up to $150 \mathrm{ng} / \mathrm{L}$; HMUD was below LOQ (Steverkooperation 2016). The herbicide nicosulfuron is used as post-emergence herbicide in maize cultivation (BLW 2018a, Lewis et al. 2016); sales in Switzerland are 1-5 t/a (BLW 2018b). Nicosulfuron is low to moderately persistent ( DT $_{50} 7-46 \mathrm{~d}$ ) in aerobic soils (EFSA 2008), and accordingly, was only detected in four samples at concentrations $<5 \mathrm{ng} / \mathrm{L}$.

\subsection{Agricultural vs. Urban Pollution}

The target and suspect screening showed clearly that not only pesticides but also their TPs need to be monitored to comprehensively assess the impact of pesticide application in agriculture on groundwater quality. Although we quantitatively analysed more pesticides than pesticide TPs (176 vs. 97), the total concentration of pesticide TPs exceeded the total concentration of the active substances in 30 samples. This holds also true for individual pesticides: most active substances were detected less frequently and at lower concentrations than the sum of their TPs (Figure 3 ) as was also reported in the Swiss National Groundwater Monitoring NAQUA (FOEN 2019, Reinhardt et al. 2017) and research studies (Buttiglieri et al. 2009, Kolpin et al. 2004, Weber et al. 2007). These findings coincide with substance properties such as $\mathrm{DT}_{50}$ and $\mathrm{K}_{\mathrm{fOC}}$ (EFSA peer review reports, if available) and predicted $\log \mathrm{D}_{\mathrm{pH}}$ values. The pesticide TPs often show higher persistence and mobility than the active substance.

To assess to what extent the selected groundwater samples were polluted by agricultural and/or urban influences, we screened additionally for $283 \mathrm{MPs}$ from predominantly urban sources. Although the quantitative screening comprised approximately as many agricultural as urban MPs (273 vs. 283), the total concentration and detection frequency of agricultural MPs exceeded the concentration and detection frequency of urban MPs in 26 and 28 samples, respectively. The dominance of agricultural MPs was expected, as we predominantly selected groundwater monitoring sites which were known to be impacted by agricultural MPs, to cover groundwater contamination with pesticide TPs as comprehensively as possible. Nevertheless, eleven samples were clearly impacted by urban contamination sources, revealing at least ten different urban MPs. Figure 4 illustrates the MP pattern and land use in the catchment of the 31 sampled aquifers. 


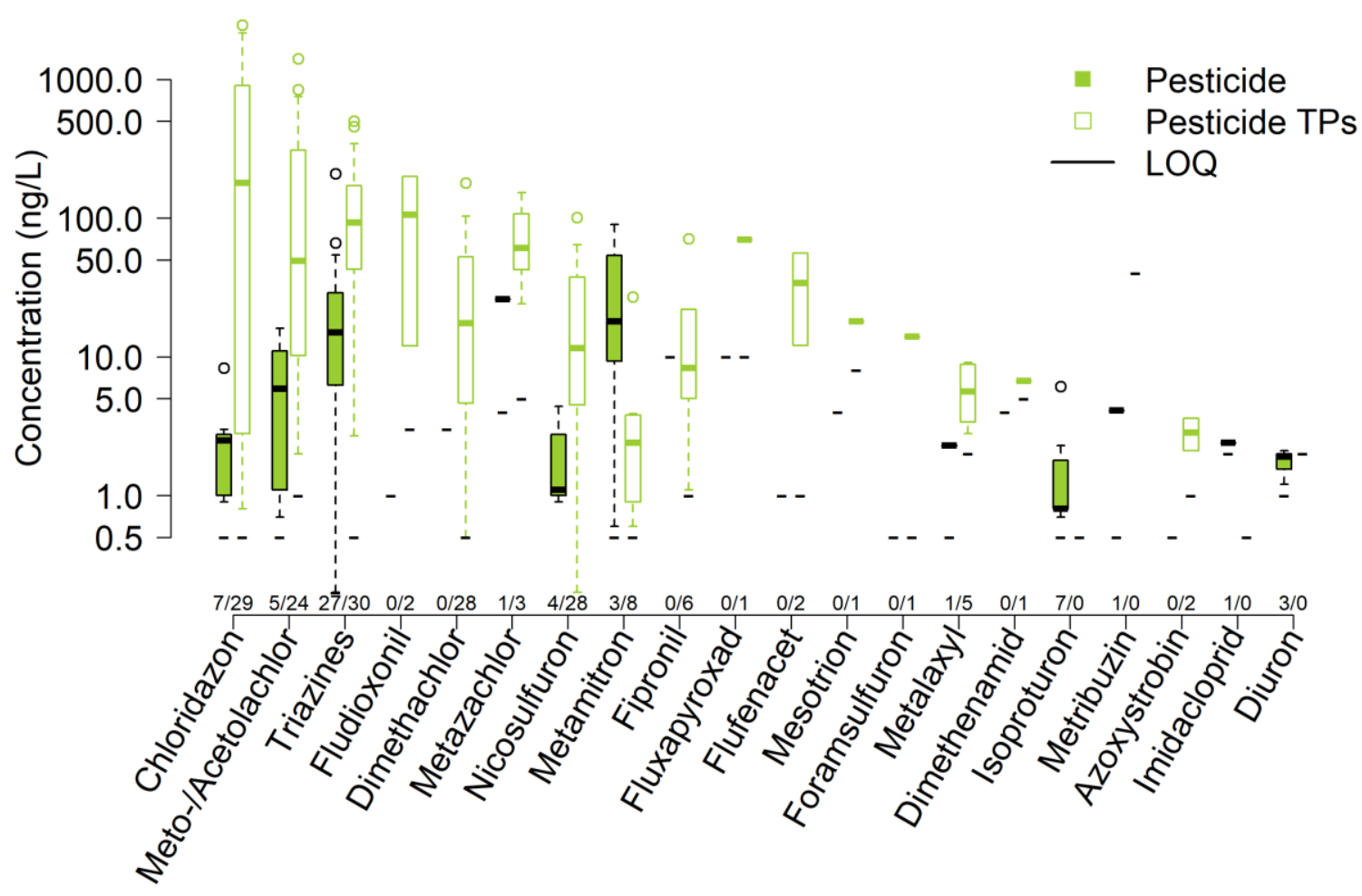

Figure 3: The total concentration of active substance (in filled boxes) compared to the pesticide TPs (in open boxes). In almost all cases the total concentration of TPs is higher than the concentration of the active substance. Numbers above $x$-axis indicate the detection frequency of the active substance / TPs in the 31 samples. Total concentration is plotted on the y-axis on a logarithmic scale. Compounds are ordered by decreasing maximum concentration. Triazines were summarised, as many TPs may originate from different triazines. Pesticides for which only TPs could be analysed with the analytical method are not included (e.g. chlorothalonil). Metolachlor-ESA was not analysed in all samples due to RT shifts.

The presence of agricultural and urban MPs in the individual groundwater samples is partly explained by the land use within the catchments. The percentage of agricultural land in the catchments correlated weakly with the total concentration of agricultural MPs (Pearson's $\rho$ 0.50) and with detection frequency ( $\rho$ 0.34), respectively (see Figure SI-A 7). Land use probably correlated more strongly with concentration than with detection frequency, as the agricultural area influences more the amount than the number of applied pesticides. Surprisingly, the groundwater monitoring site with the highest percentage of agriculture in the catchment showed only a low concentration of agricultural MPs $(220 \mathrm{ng} / \mathrm{L}$,

Figure 4, Figure SI-A 7). Total MP concentration at this location was dominated by the widespread and highly mobile chlorothalonil TP R471811, accounting for $84 \%$ of total MP concentration. The low contamination with agricultural MPs may be explained by the hydrogeological setting. According to borehole logs, the groundwater well abstracts water from a heterogeneous aquifer consisting of sand-loam layers with gravel lentils / channels. Furthermore, the borehole logs show less permeable loam-clay top layers, which may act as a protective barrier, reducing MP transport from the surface. This explains both the low MP concentration, low nitrate concentration $(10 \mathrm{mg} / \mathrm{L})$, and the low oxygen content (oxygen content during sampling: $0.5 \mathrm{mg} / \mathrm{L}$, dissolved organic carbon content: $<0.5$ $\mathrm{mg} / \mathrm{L}$ ). If this sample is excluded as outlier, the correlation between percentage of agricultural land and agricultural MP concentration increases from $\rho 0.50$ to $\rho 0.64$. 


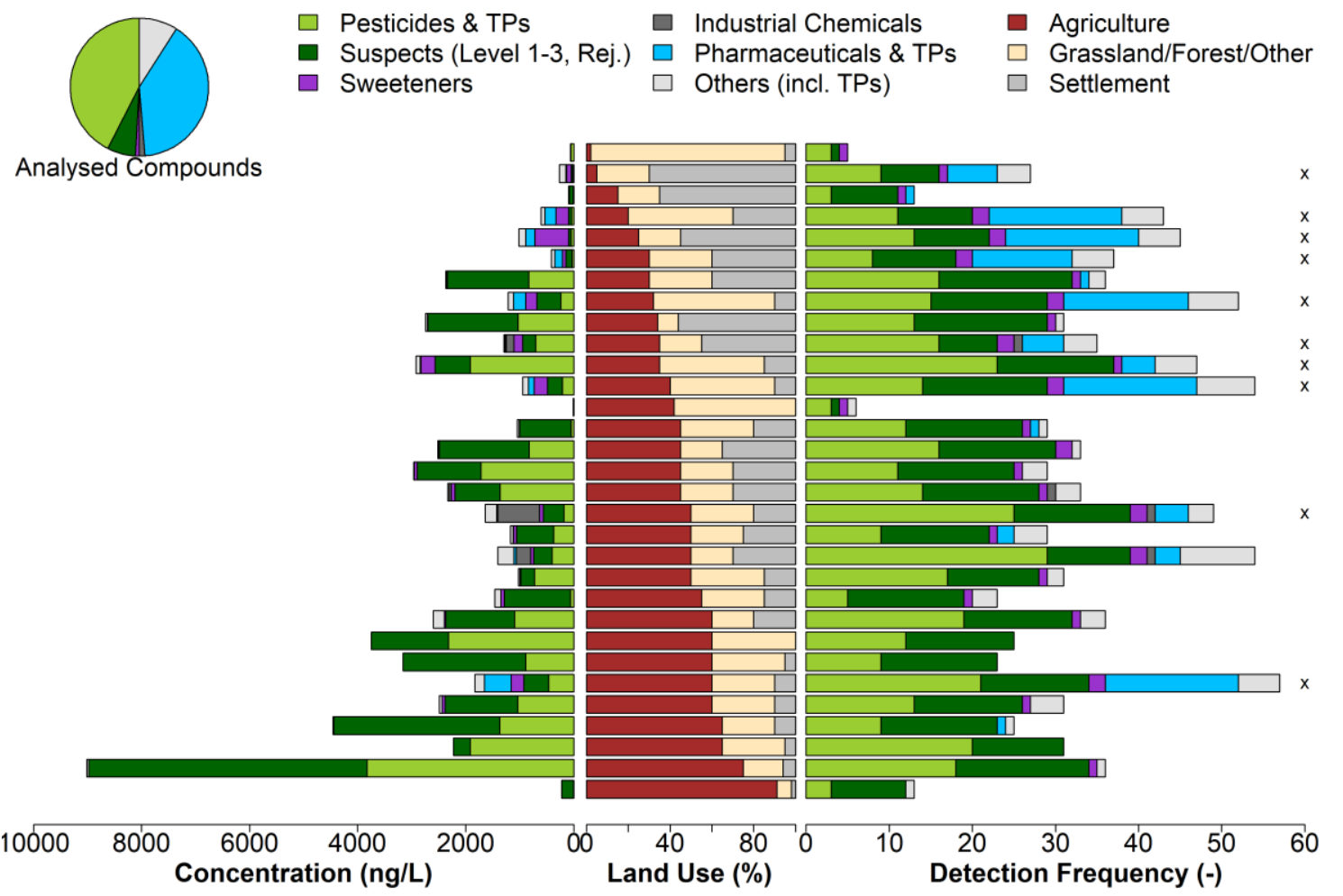

Figure 4: Total concentration (left) and detection frequency (right) per compound class and sample compared to land use. In the centre, land use in the catchment of each groundwater monitoring site. In the upper left, pie chart with the distribution of all quantitatively analysed substances in compound classes. Suspects: pesticides and pesticide TPs which were confirmed and quantified (Levels 1-3) or rejected with reference standards. Agricultural MPs: pesticides and suspects. Urban MPs: sweeteners, industrial chemicals, pharmaceuticals and others. " $X$ " marks groundwater monitoring sites close to wastewater impacted streams $(<700 \mathrm{~m}$, river bank filtration). Monitoring sites are ordered from top to bottom by increasing agricultural land use. The pesticide TP metolachlor-ESA could not be analysed in all samples due to RT shift.

While agricultural pollution seems to be related to agricultural land use area, no or only a very weak correlation was found between urban MP concentration/detection frequency, and percentage of settlement in the catchment (Pearson's $\rho$ 0.14/0.21, see Figure SI-A 7). The low correlation shows the different entry pathways for agricultural and urban MPs. Pesticides and their TPs predominantly enter groundwater diffuse via seepage from agricultural soils, whereas, urban MPs enter groundwater primarily along wastewater impacted streams or leaky sewer systems. While streams are not considered in the land use characterisation of the monitoring sites, sewer systems are covered by the land use class "settlement". Ten out of eleven samples with at least ten different urban MPs originated from groundwater monitoring sites which are located 30 to $700 \mathrm{~m}$ from a wastewater impacted stream (river bank filtration, Figure 4). The groundwater monitoring site without river bank filtration influence, however, drains a catchment with a sewer, which may explain the presence of 16 different urban MPs in addition to the 40 agricultural MPs. Especially in urban areas, leaky sewer systems were shown to present a major contamination source for groundwater (Wolf et al. 2012). Similar observations were made by Ter Laak et al. (2012) in a Dutch groundwater screening study comprising 42 pumping wells differing in the hydrogeological setting (river bank filtration, phreatic, and (semi-) confined) and the land use. Ter Laak et al. (2012) detected more compounds in groundwater from rural than from urban areas. However, most of these compounds 
found in rural areas could not be identified, possibly because the target screening was only comprised of a few pesticides and TPs. See SI-A 6 for further discussion of site-specific MP contamination.

\section{Conclusions}

- Suspect screening with a high-quality suspect list comprising more than 1000 experimentally observed pesticide TPs revealed the presence of several so far overseen pesticide TPs in groundwater. The suspect list presented is currently the most comprehensive pesticide TP data set which is publicly accessible and is recommended for screening surface and groundwaters worldwide.

- The suspect screening identified 27 pesticides and pesticide TPs (Levels 1-3). The TPs of chlorothalonil, nicosulfuron, fipronil, terbuthylazine, bixafen and fluxapyroxad were so far rarely mentioned in literature or not known at all. Spectra for future screening studies are available on MassBank (www.massbank.eu).

- Chlorothalonil TPs were widely present in groundwater. Chlorothalonil TP R471811 was detected in all samples, even in aquifers with low anthropogenic impact. In 20 out of 31 samples, concentrations exceeded $100 \mathrm{ng} / \mathrm{L}$. The human-toxicological risk needs to be assessed as well as the fate in drinking water treatment.

- Total MP concentrations ranged from 60 to $9000 \mathrm{ng} / \mathrm{L}$. The MPs with the highest concentration and detection frequency were pesticide TPs followed by parent pesticides (detection frequency) and sweeteners (concentration). Concentrations of 15 TPs originating from nine different pesticides exceeded $100 \mathrm{ng} / \mathrm{L}$ in at least one sample.

- Land use in the catchment and hydrogeological setting (river bank filtration, top layers) strongly drove the MP pattern. Urban MPs were predominantly detected in aquifers that interact with wastewater impacted streams. Agricultural MPs were found in aquifers with agriculture in the catchment.

\section{Acknowledgement}

This study was funded by the Swiss Federal Office for the Environment FOEN and the Swiss National Science Foundation (grant number 205320_165935). Samples of the National Groundwater monitoring NAQUA were provided by the Federal Office for the Environment FOEN and the cantonal authorities. Groundwater monitoring sites were selected by Miriam Reinhardt. We are grateful to all those involved in sample collection and transport and to the Eawag AuA laboratory for analysing various hydrochemical parameters. The comprehensive list of pesticides approved in Switzerland 2005-2017 was provided by the Swiss Water Pollution Control Association platform (VSA-Platform). Additionally, we thank Kathrin Fenner, Diogo Latino and co-workers for the extensive list of pesticide TPs that were extracted manually from European pesticide registration dossiers in a labour-intensive process. We especially thank Philipp Longrée for his support in lab work, LC-HRMS measurement and target quantification. Furthermore, we acknowledge Emma Schymanski for her support in compiling the suspect list and for providing an R script to run MetFrag in an automated way for all suspect hits. We thank Jennifer Schollée and Michael Stravs for their help with $\mathrm{R}$, and additionally, Jennifer Schollée and Miriam Reinhardt for proofreading the manuscript and their critical feedback. Finally, we acknowledge Syngenta, BASF, Dupont and Bayer for providing reference material. 


\section{References}

2004/248/EC, 2004. Commission decision of 10 March 2004 concerning the non-inclusion of atrazine in Annex I to Council Directive 91/414/EEC and the withdrawal of authorisations for plant protection products containing this active substance. Official Journal of the European Union 78, 1-3.

Alvarez, P.M., Quinones, D.H., Terrones, I., Rey, A. and Beltran, F.J., 2016. Insights into the removal of terbuthylazine from aqueous solution by several treatment methods. Water research $98,334-$ 343.

Arp, H.P.H., Brown, T.N., Berger, U. and Hale, S.E., 2017. Ranking REACH registered neutral, ionizable and ionic organic chemicals based on their aquatic persistency and mobility. Environmental Science: Processes \& Impacts 19(7), 939-955.

Banning, H., Bialek, K., Czub, G., Müller, A., Pickl, C., Scheithauer, M., Straus, G. and Tüting, W., 2019. Recommendation list for the monitoring of pesticide metabolites in German groundwaters (Empfehlungsliste für das Monitoring von Pflanzenschutzmittel-Metaboliten in deutschen Grundwässern). UBA. https://www.umweltbundesamt.de/dokument/empfehlungsliste-fuerdas-monitoring-von. Accessed: 25/06/2019.

BLW, 2018a. List of approved plant protection products (Pflanzenschutzmittelverzeichnis). Federal Office for the Agriculture. https://www.psm.admin.ch/de/produkte. Accessed: 18/12/2018.

BLW, 2018b. Sales per active ingredient (Verkaufsmengen je Pflanzenschutzmittel-Wirkstoff). Federal Office for the Agriculture. https://www.blw.admin.ch/blw/de/home/nachhaltigeproduktion/pflanzenschutz/pflanzenschutzmittel/verkaufsmengen-der-pflanzenschutzmittelwirkstoffe.html. Accessed: 18/01/2019.

BLW, 2019. Relevance of plant protection product metabolites in groundwater and drinkingwater (Relevanz von Pflanzenschutzmittel-Metaboliten im Grund- und Trinkwasser). Federal Office for the Agriculture, Agroscope, Federal Food Safety and Veterinary Office. https://www.blw.admin.ch/blw/de/home/nachhaltigeproduktion/pflanzenschutz/pflanzenschutzmittel/nachhaltige-anwendung-undrisikoreduktion.html. Accessed: 18/01/2019.

Brunner, A.M., Vughs, D., Siegers, W., Bertelkamp, C., Hofman-Caris, R., Kolkman, A. and ter Laak, T., 2019. Monitoring transformation product formation in the drinking water treatments rapid sand filtration and ozonation. Chemosphere 214, 801-811.

Buttiglieri, G., Peschka, M., Fromel, T., Muller, J., Malpei, F., Seel, P. and Knepper, T.P., 2009. Environmental occurrence and degradation of the herbicide $n$-chloridazon. Water research 43(11), 2865-2873.

Chambers, M.C., Maclean, B., Burke, R., Amodei, D., Ruderman, D.L., Neumann, S., Gatto, L., Fischer, B., Pratt, B., Egertson, J., Hoff, K., Kessner, D., Tasman, N., Shulman, N., Frewen, B., Baker, T.A., Brusniak, M.-Y., Paulse, C., Creasy, D., Flashner, L., Kani, K., Moulding, C., Seymour, S.L., Nuwaysir, L.M., Lefebvre, B., Kuhlmann, F., Roark, J., Rainer, P., Detlev, S., Hemenway, T., Huhmer, A., Langridge, J., Connolly, B., Chadick, T., Holly, K., Eckels, J., Deutsch, E.W., Moritz, R.L., Katz, J.E., Agus, D.B., MacCoss, M., Tabb, D.L. and Mallick, P., 2012. A cross-platform toolkit for mass spectrometry and proteomics. Nature Biotechnology 30, 918.

Daughton, C.G. and Ternes, T.A., 1999. Pharmaceuticals and personal care products in the environment: agents of subtle change? Environmental health perspectives 107 Suppl 6, 907938. 
Duhrkop, K., Shen, H., Meusel, M., Rousu, J. and Bocker, S., 2015. Searching molecular structure databases with tandem mass spectra using CSI:FingerID. Proc Natl Acad Sci U S A 112(41), 12580-12585.

EDI, 2016. Swiss regulation No. 817.022.11 concerning drinking water and water in public swimming pools and shower facilities (Verordnung des EDI über Trinkwasser sowie Wasser in öffentlich zugänglichen Bädern und Duschanlagen (TBDV) vom 16. Dezember 2016 (Stand am 1. Mai 2018)), Eidgenössisches Departement des Innern.

EFSA, 2008. Conclusion regarding the peer review of the pesticide risk assessment of the active substance nicosulfuron. EFSA Journal 120, 1-91.

EFSA, 2017. Peer review of the pesticide risk assessment for the active substance terbuthylazine in light of confirmatory data submitted. EFSA Journal 15(6), 1-20.

EFSA, 2018. Peer review of the pesticide risk assessment of the active substance chlorothalonil. EFSA Journal 16(1), 1-40.

European Commission, 1998. Council Directive 98/83/EC of 3 November 1998 on the quality of water intended for human consumption. Official Journal of the European Communities (L330).

European Commission, 2003. Guidance document on the assessment of the relevance of metabolites in groundwater of substances regulated under council directive 91/414/EEC. Sanco/221/2000 -rev.10- final.

European Commission, 2019. SANTE/10186/2018 Rev 1: Final Renewal report for the active substance chlorothalonil finalised in the Standing Committee on Plants, Animals, Food and Feed at its meeting on 22 March 2019 in view of the non-renewal of the approval of chlorothalonil as active substance in accordance with Regulation (EC) No 1107/20091. https://ec.europa.eu/food/plant/pesticides/eu-pesticides-

database/public/?event=activesubstance.ViewReview\&id=1720. Accessed: 05/08/2019.

FOEN, 2019. Plant protection products in groundwater. Federal Office for the Environment. https://www.bafu.admin.ch/bafu/de/home/themen/wasser/fachinformationen/zustand-dergewaesser/zustand-des-grundwassers/grundwasser-qualitaet/pflanzenschutzmittel-imgrundwasser.html. Accessed: 15/08/2019.

Freiburghaus, M., 2012. Statistical overview of water supply in Switzerland 2010 (Statistische Übersicht über die Wasserversorgung in der Schweiz 2010). Aqua \& Gas 3, 54-59.

Gatto, L. and Lilley, K.S., 2012. MSnbase - an R/Bioconductor package for isobaric tagged mass spectrometry data visualization, processing and quantitation. Bioinformatics (28), 288-289.

Heberer, T., Mechlinski, A., Fanck, B., Knappe, A., Massmann, G., Pekdeger, A. and Fritz, B., 2004. Field studies on the fate and transport of pharmaceutical residues in bank filtration. Ground Water Monitoring and Remediation 24(2), 70-77.

Horai, H., Arita, M., Kanaya, S., Nihei, Y., Ikeda, T., Suwa, K., Ojima, Y., Tanaka, K., Tanaka, S., Aoshima, K., Oda, Y., Kakazu, Y., Kusano, M., Tohge, T., Matsuda, F., Sawada, Y., Hirai, M.Y., Nakanishi, H., Ikeda, K., Akimoto, N., Maoka, T., Takahashi, H., Ara, T., Sakurai, N., Suzuki, H., Shibata, D., Neumann, S., lida, T., Tanaka, K., Funatsu, K., Matsuura, F., Soga, T., Taguchi, R., Saito, K. and Nishioka, T., 2010. MassBank: a public repository for sharing mass spectral data for life sciences. Journal of Mass Spectrometry 45(7), 703-714.

Kern, S., Fenner, K., Singer, H.P., Schwarzenbach, R.P. and Hollender, J., 2009. Identification of Transformation Products of Organic Contaminants in Natural Waters by Computer-Aided Prediction and High-Resolution Mass Spectrometry. Environmental science \& technology 43(18), 7039-7046. 
Kolpin, D.W., Schnoebelen, D.J. and Thurman, E.M., 2004. Degradates Provide Insight to Spatial and Temporal Trends of Herbicides in Ground Water. Ground Water 42(4), 601-608.

Kolpin, D.W., Thurman, E.M., Linhart, S.M.J.A.o.E.C. and Toxicology, 1998. The Environmental Occurrence of Herbicides: The Importance of Degradates in Ground Water. 35(3), 385-390.

Lapworth, D.J., Baran, N., Stuart, M.E. and Ward, R.S., 2012. Emerging organic contaminants in groundwater: A review of sources, fate and occurrence. Environmental pollution 163, 287-303.

Latino, D.A., Wicker, J., Gutlein, M., Schmid, E., Kramer, S. and Fenner, K., 2017. Eawag-Soil in enviPath: a new resource for exploring regulatory pesticide soil biodegradation pathways and half-life data. Environmental Science Processes and Impacts 19, 449-464.

Lewandowski, J., Putschew, A., Schwesig, D., Neumann, C. and Radke, M., 2011. Fate of organic micropollutants in the hyporheic zone of a eutrophic lowland stream: Results of a preliminary field study. Science of The Total Environment 409(10), 1824-1835.

Lewis, K.A., Tzilivakis, J., Warner, D.J. and Green, A., 2016. An international database for pesticide risk assessments and management. Human and Ecological Risk Assessment: An International Journal 22(4), 1050-1064.

LfU, 2018. Development of PPP pollution in Bavarian waters - balance after 30 years of PSM monitoring. (Entwicklung der PSM-Belastung in bayerischen Gewässern - Bilanz nach 30 Jahren PSM-Monitoring). Bayerisches Landesamt für Umwelt. http://www.bestellen.bayern.de/shoplink/Ifu all 00146.htm.

Loos, R., Locoro, G., Comero, S., Contini, S., Schwesig, D., Werres, F., Balsaa, P., Gans, O., Weiss, S., Blaha, L., Bolchi, M. and Gawlik, B.M., 2010. Pan-European survey on the occurrence of selected polar organic persistent pollutants in ground water. Water research 44(14), 41154126.

LUBW, 2011. Groundwater monitoring programme - results from sampling campaign 2010 (Grundwasserüberwachungsprogramm - Ergebnisse der Beprobung 2010). Reihe Grundwasserschutz. 42, 1-98. http://www4.lubw.baden-wuerttemberg.de/servlet/is/208632/.

Matsushita, T., Morimoto, A., Kuriyama, T., Matsumoto, E., Matsui, Y., Shirasaki, N., Kondo, T., Takanashi, H. and Kameya, T., 2018. Removals of pesticides and pesticide transformation products during drinking water treatment processes and their impact on mutagen formation potential after chlorination. Water research 138, 67-76.

Mechelke, J., Longree, P., Singer, H. and Hollender, J., 2019. Vacuum-assisted evaporative concentration combined with LC-HRMS/MS for ultra-trace-level screening of organic micropollutants in environmental water samples. Analytical and Bioanalytical Chemistry.

MoNA, 2019. MoNA - MassBank of North America. http://mona.fiehnlab.ucdavis.edu/. Accessed: 21/01/2019.

Moschet, C., Piazzoli, A., Singer, H. and Hollender, J., 2013. Alleviating the reference standard dilemma using a systematic exact mass suspect screening approach with liquid chromatography-high resolution mass spectrometry. Analytical chemistry 85(21), 10312 10320.

Postigo, C. and Barcelo, D., 2015. Synthetic organic compounds and their transformation products in groundwater: occurrence, fate and mitigation. Science of The Total Environment 503-504, 3247.

R Core Team, 2016. R: A language and environment for statistical computing. R Foundation for Statistical Computing, Vienna, Austria. https://www.R-project.org/. 
Reemtsma, T., Alder, L. and Banasiak, U., 2013a. Emerging pesticide metabolites in groundwater and surface water as determined by the application of a multimethod for 150 pesticide metabolites. Water research 47(15), 5535-5545.

Reemtsma, T., Alder, L. and Banasiak, U., 2013b. A multimethod for the determination of 150 pesticide metabolites in surface water and groundwater using direct injection liquid chromatography-mass spectrometry. Journal of chromatography A 1271(1), 95-104.

Reemtsma, T., Berger, U., Arp, H.P., Gallard, H., Knepper, T.P., Neumann, M., Quintana, J.B. and Voogt, P., 2016. Mind the Gap: Persistent and Mobile Organic Compounds-Water Contaminants That Slip Through. Environmental science \& technology 50(19), 10308-10315.

Reinhardt, M., Kozel, R., Hofacker, A. and Leu, C., 2017. Monitoring of pesticide residues in groundwater (Monitoring von PSM-Rückständen im Grundwasser). Aqua \& Gas 6, 78-89.

RSC, 2018. ChemSpider, Royal Society of Chemistry. http://www.chemspider.com/.

Ruttkies, C., Schymanski, E.L., Wolf, S., Hollender, J. and Neumann, S., 2016. MetFrag relaunched: incorporating strategies beyond in silico fragmentation. Journal of Cheminformatics 8(3).

Schollée, J.E., 2017. MSMSsim: Functions for processing HRMS2 spectra from output from RMassBank, mainly for calculating spectral similarity. https://github.com/dutchjes/MSMSsim.

Schymanski, E.L., Jeon, J., Gulde, R., Fenner, K., Ruff, M., Singer, H.P. and Hollender, J., 2014. Identifying small molecules via high resolution mass spectrometry: communicating confidence. Environmental science \& technology 48(4), 2097-2098.

Smith, C.A., Maille, G.O., Want, E.J., Qin, C., Trauger, S.A., Brandon, T.R., Custodio, D.E., Abagyan, R. and Siuzdak, G., 2005. METLIN: A Metabolite Mass Spectral Database. Therapeutic Drug Monitoring 27(6), 747-751.

Steverkooperation, 2016. Cooperation agriculture and water management in the catchment of the Sterver dam (Kooperation Landwirtschaft und Wasserwirtschaft im Einzugsgebiet der Stevertalsperre - Ein Bericht über die Ergebnisse der Beratung in 2015). Kooperation Land- und Wasserwirtschaft im Einzugsgebiet der Stevertalsperre. http://www.ackersaatbau.de/images/PDF/Steverakte2015.pdf. Accessed: 18/01/2019.

Ter Laak, T.L., Puijker, L.M., van Leerdam, J.A., Raat, K.J., Kolkman, A., de Voogt, P. and van Wezel, A.P., 2012. Broad target chemical screening approach used as tool for rapid assessment of groundwater quality. Science of The Total Environment 427-428, 308-313.

Valsecchi, S., Mazzoni, M., Rusconi, M., Polesello, S., Sala, A., Longoni, O. and Rusconi, M., 2017. Spread and risk assessment of LM6, a non-chlorinated metabolite of terbuthylazine, in groundwater (Diffusione e valutazione di rischio di LM6, metabolita non clorurato della terbutilazina, nelle falde acquifere). Ingegneria dell'Ambiente 4(2), 131-141.

Von Sonntag, C. and Von Gunten, U., 2012. Chemistry of Ozone in Water and Wastewater Treatment: From Basic Principles to Applications, IWA Publisher, London.

Weber, W.H., Seitz, W. and Schulz, W., 2007. Detection of the metabolites desphenyl-chloridazone and methyl-desphenyl-chloridazone in surface, ground and drinking water (Nachweis der Metaboliten Desphenyl-Chloridazon und Methyldesphenyl-chloridazon in Oberflächen-, Grund- und Trinkwasser). Vom Wasser 105, 7-14.

Wolf, L., Zwiener, C. and Zemann, M., 2012. Tracking artificial sweeteners and pharmaceuticals introduced into urban groundwater by leaking sewer networks. Science of The Total Environment 430, 8-19. 